\title{
Úlcera rectal penetrada a espacio presacro
}

\author{
J. Egea Valenzuela, A. Sánchez Torres, M. Alajarín Cervera, J. Gil Martínez y y F. Carballo Álvarez \\ Servicios de Medicina del Aparato Digestivo y ${ }^{1}$ Cirugía General. Hospital Universitario Virgen de la Arrixaca. Murcia
}

\section{CASO CLÍNICO}

Una mujer de 62 años de edad consulta en área de urgencias de nuestro hospital por cuadro de rectorragia franca. En la valoración inicial presentaba estabilidad clínica y hemodinámica, siendo la exploración física anodina salvo el tacto rectal que fue muy doloroso y con presencia de sangre en recto. La hemoglobina y el hematocrito se mantuvieron en rango de normalidad, mientras que presentaba una sobredosificación de dicumarínicos con INR: 6.3.

Como antecedente inmediato destaca que la enferma venía presentando en los días previos un cuadro gripal que estaba tratando de modo sintomático. El día anterior al de su consulta refiere haberse administrado un supositorio de diclofenaco.

A pesar de la corrección de las alteraciones de la coagulación con administración de vitamina $\mathrm{K}$ y plasma, persistió una rectorragia cuantiosa, que anemizó a la paciente, lo que obligó a la transfusión de 2 unidades de concentrados de hematíes. Se realizó una colonoscopia, que mostró una laceración profunda, a unos 7-8 $\mathrm{cm}$ del margen anal, de bordes

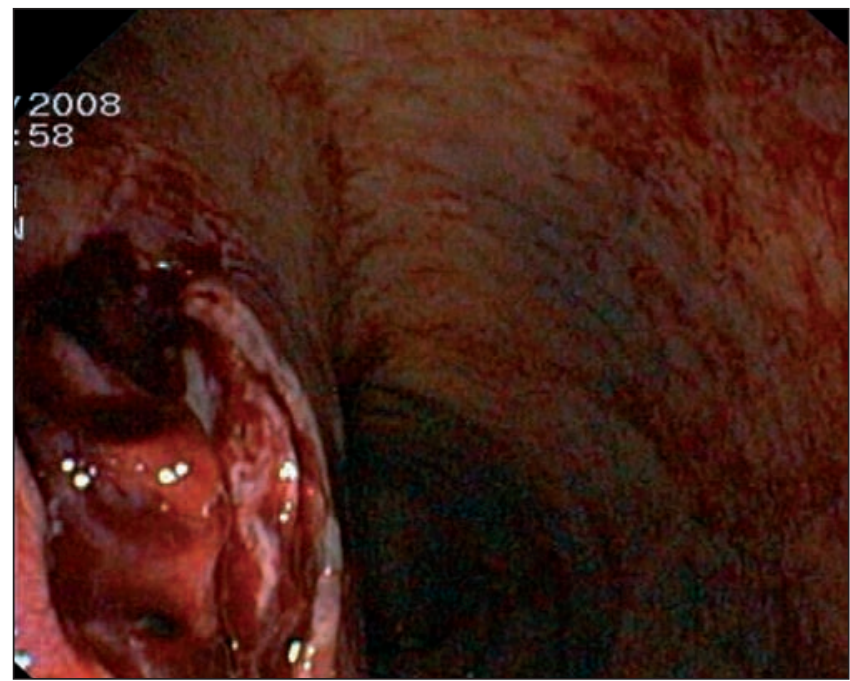

Fig. 1. Imagen endoscópica de la perforación, aproximadamente a unos 7-8 cm de margen anal. En los bordes de la ulceración se aprecia la presencia de fibras musculares, lo que da idea de la profundidad de la lesión. irregulares, en los que parecen apreciarse tejido muscular y aponeurótico (Fig. 1). Con posterioridad se habría de someter a la paciente a un TAC, que confirmó la sospecha de perforación rectal y evidenció igualmente un hematoma perirrectal de 6,5 cm de diámetro con burbujas aéreas en relación con esta (Figs. 2 y 3 ).

Diagnóstico: úlcera rectal perforada a espacio presacro en relación a tratamiento de diclofenaco en supositorio.

En coordinación con el servicio de cirugía de nuestro hospital se decidió actitud expectante, mejorando la paciente progresivamente del dolor y la sensación de ocupación perineal y desapareciendo la rectorragia en días ulteriores.

\section{COMENTARIOS}

La ulceración rectal perforada es una patología poco frecuente y escasamente descrita en la literatura. Si bien son abundantes las referencias a perforaciones neoplásicas o iatrógenas, no es así en lo referente a las causadas por cuerpos extraños o, como en nuestro caso, por aplicación de fármacos de acción o absorción local. En cualquier caso, se recomienda un tratamiento estandarizado y personalizado, dependiendo de las condiciones del enfermo, el tipo de perforación y las posibles complicaciones. 


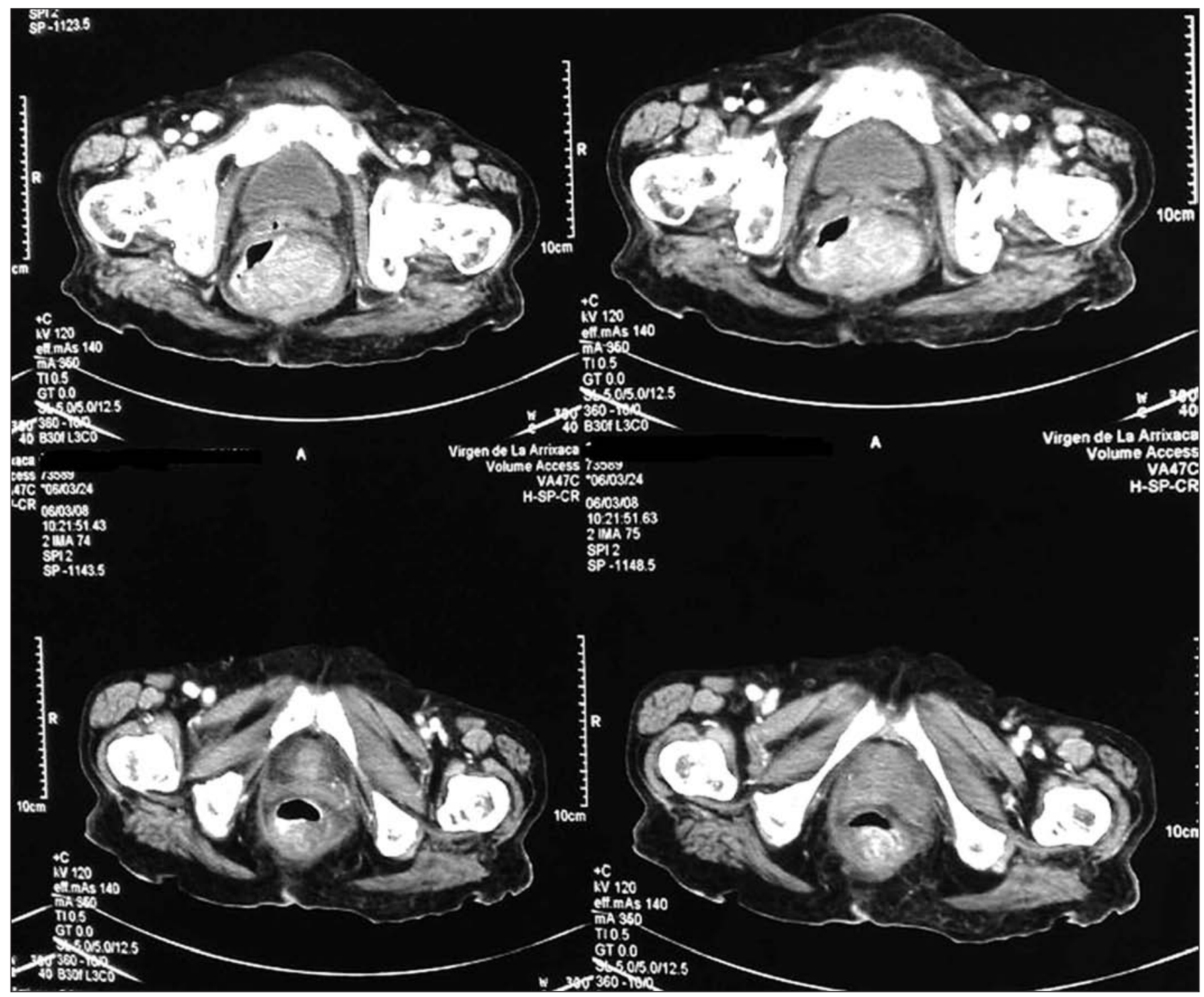

Fig. 2. Imágenes de TAC donde se pone de manifiesto la presencia de un gran hematoma perirrectal de unos $6,5 \mathrm{~cm}$.

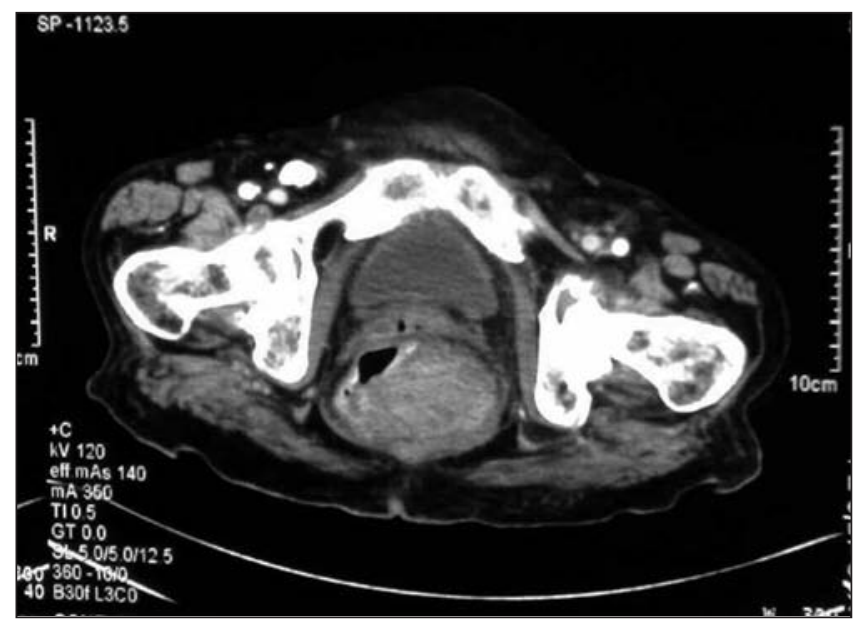

\section{BIBLIOGRAFÍA}

1. Di Venere B, Testini M, Miniello S, Piccinni G, Lissidini G, Carbone F, et al. Rectal perforations. Personal experience and literature review. Minerva Chir 2002; 57 (3): 357-62.

2. Eu KW, Seow-Choen F, Goh HS. Unusual rectal perforation--an individualised approach to management. Singapore Med J 1994; 35 (1): 79-81.

3. Marti MC, Morel P, Rohner A. Traumatic lesions of the rectum. Int J Colorectal Dis 1986; 1 (3): 152-4.

Fig. 3. Detalle del hematoma perirrectal observado en TAC. 